\title{
Characteristics of taste dysfunction in COVID-19 subjects coming from two different countries
}

\author{
Alfonso Luca Pendolino ${ }^{1,2}$ (1) Giancarlo Ottaviano ${ }^{3}$ (D) Bruno Scarpa ${ }^{4} \cdot$ Annamaria Cattelan $^{5} \cdot$ Julie A. Andrews $^{6}$. \\ Peter J. Andrews ${ }^{1,2}$ (1)
}

Received: 4 October 2020 / Revised: 3 December 2020 / Accepted: 11 January 2021 / Published online: 22 March 2021

(c) The Author(s) 2021

\begin{abstract}
Taste dysfunction (TD) has been recognised, together with olfactory dysfunction, as a key presenting symptom of COVID19. The capability to recognise flavours, flavour intensities and aroma characteristics can be highly variable within the same population, as well as potentially diverse between culturally different populations. The aims of this study are to evaluate whether a difference in the types of TD presentation amongst COVID-19 positive subjects can be demonstrated and whether a difference exists between populations of different cultures.
\end{abstract}

Keywords COVID-19 $\cdot$ Rhinology $\cdot$ Taste $\cdot$ Taste dysfunction $\cdot$ Survey

Taste dysfunction (TD) has been recognised, together with olfactory dysfunction, as a key presenting symptom of COVID-19, and its prevalence has been estimated to be as high as $30.4 \%$ in the general population (Bartheld et al. 2020). Most cases of TD are associated with OD suggesting that gustatory alteration is usually linked to an impairment of retronasal olfaction rather than impairment of gustation itself (Whitcroft and Hummel 2020). Nonetheless, the angiotensin-converting enzyme 2 receptor, which is the main host cell receptor of SARS$\mathrm{CoV}-2$, is widely expressed on oral mucosa epithelial cells (Xu et al. 2020) and this may explain the taste impairment

Alfonso Luca Pendolino alfonso.pendolino@nhs.net

1 Department of Ear, Nose and Throat, Royal National ENT \& Eastman Dental Hospitals, London, UK

2 Ear Institute, UCL, London, UK

3 Department of Neurosciences, Otolaryngology Section, University of Padova, Padova, Italy

4 Department of Statistical Sciences and Department of Mathematics Tullio Levi-Civita, University of Padova, Padova, Italy

5 Unit of Infectious Disease, University Hospital of Padova, Padova, Italy

6 Department of Microbiology, Whittington Health, London, UK experienced in the early stage of COVID-19 as well as the more rare cases of isolated TD (Bartheld et al. 2020).

The capability to recognise flavours, flavour intensities and aroma characteristics can be highly variable within the same population (Doty 2019), as well as potentially diverse between culturally different populations. Certain populations may be more prone to detect a TD if a particular flavour which they have been accustomed to has been affected (Sjöstrand et al. 2020).

To the best of our knowledge, characteristics of TD presentation amongst COVID-19 positive subjects have not been evaluated and the differences in TD presentation between culturally different populations have not been assessed. The aims of this study are to evaluate whether a difference in the types of TD presentation amongst COVID-19 positive subjects can be demonstrated and whether a difference exists between populations of different cultures.

Between May 26 and June 10, 2020, we conducted a survey in two European hospitals (London (UK) and Padua (Italy)) on COVID-19 positive subjects who complained of olfactory and/or taste dysfunction during the course of their disease (Andrews et al. 2020). The recipients of this survey were mild-to-moderate symptomatic COVID-19 positive health-care workers who tested positive by RT-PCR for SARS-CoV-2 and were working at their own hospital during COVID-19 pandemic. Participants were selected using the databases 
of the Microbiology Laboratory in London and the Infectious Disease Department in Padua. The study was approved by the UCL Research Ethics Committee (IRAS 156511), the UCL joint research office and the Padua Otolaryngology Section's in-house ethical committee (n 056881). The survey questionnaire was validated by both ENT and infection clinicians as well as patient advocates to ensure clarity and to exclude ambiguity. All respondents were invited to take part in this survey via email which included a study information pack and a consent form. Those who accepted and signed the consent form received the questionnaire via email in London and by hand in Padua. Inclusion criteria were age $>18$ years old, laboratory confirmation of SARS-CoV-2 infection, subjects with mild-to-moderate symptoms (defined as homemanaged subjects with symptoms not requiring intensive care or hospital admission), good comprehension of the language used in the questionnaire and absence of any clinical impairment to complete the questionnaire. For the specific aim of the study, only those participants with a reported taste impairment at the moment of questionnaire administration were considered. Subjects with a past history of TD or those whose sense of taste had completely recovered at the moment of the survey were excluded.

Impairment of the four main flavours in addition to water, which has recently been shown to be tasted as a separate flavour (Sjöstrand et al. 2020; Rimmer et al. 2019), was investigated. Specifically, the participants had to mark which of the listed flavours they were no longer able to taste. Furthermore, they were asked if they had a distortion of the taste (dysgeusia), namely if they still continued to detect the different flavours but distorted. We excluded the flavour 'umami' because of its significant variability in recognition amongst different populations (Sjöstrand et al. 2020). Quantitative variables were compared using the Wilcoxon test while binary variables using the Fisher's exact test. The heterogeneity within samples was tested with pairwise comparison of prevalence adjusted by the Holm correction. The chi-square test was adopted to compare the frequencies of the numbers of flavours affected within samples.

One-hundred and fifty-five HCWs, 119 from London and 36 from Padua, received the questionnaire. The different method of questionnaire administration led to a different response rate of $70.6 \%$ (84/119) in London and of $100 \%$ (36/36) in Padua. After further analysis, we excluded 2 participants who did not accept the consent form and 4 participants who did not answer any question, leading to a final population of $114 \mathrm{HCWs}$ who completed the initial survey. Among them, only 47 subjects, 23 Londoners and 24 Paduans, were still complaining of TD when questionnaire was administered and were finally considered for the analysis. The majority of the participants were female, middle-aged, white and reported TD to be associated with OD (Table 1). When comparing the two hospitals, a statistically significant difference was observed in the reported affected flavours (sour and bitter higher among Londoners) and the presence of distortion of taste (dysgeusia higher among Paduans). Additionally, a statistically significant difference in the ethnical composition was noted when comparing the two samples. Apart from a significantly higher rate of white subjects in the London group and of dysgeusia reported by the Italian participants, no other statistically significant differences were found when looking at the two populations separately (Table 1).

A difference in the presentation of TD between the London and Padua populations was observed with respect to flavour type being affected and dysgeusia. Particularly, a loss in the flavour of sour and bitter was clearly reported by Londoners, whereas the Italian participants reported a significantly higher rate of taste distortion (dysgeusia). When looking at the single populations separately, it would appear the London population has a more severe TD with a higher number of flavour types being affected compared with the Paduan population. However, we did not show that a specific flavour or number of flavours being affected occurred more commonly as a result of SARS-CoV-2 infection $(p=1)$.

Our results demonstrate a statistically significant disparity in taste perception between the two countries which may be due to genetic predisposition, cultural learning or a difference threshold in the taste perception which could explain the higher rate of dysgeusia amongst Italians. Importantly, the London population was a more ethnically diverse population which may be a confounding factor. Our data also confirms previous findings that TD is more frequent amongst middle aged and female subjects and generally associated with an OD (Bartheld et al. 2020).

A limit of the study was that TD was not confirmed through psychophysical tests (Rimmer et al. 2019). However, during the present pandemic, psychophysical tests have not been available or fully feasible in many countries and, therefore, we believe that in an emergency condition self-rated symptoms remain of value.

Taken together, our results confirm that a cultural variability in taste appreciation or perception should be borne in mind when investigating subjective TD amongst COVID-19 positive subjects especially when it is considered a key symptom in COVID-19 presentation. In the future, it would be interesting to study if taste differences exist between the two countries by including healthy subjects not complaining of any TD, and, possibly, using taste strips. 
Table 1 Characteristics of taste dysfunction in the two populations

\begin{tabular}{|c|c|c|c|c|c|}
\hline & \multirow[t]{2}{*}{$\begin{array}{l}\text { London } \\
(n=23)\end{array}$} & \multirow[t]{2}{*}{$\begin{array}{l}\text { Padua } \\
(n=24)\end{array}$} & \multicolumn{2}{|c|}{$\begin{array}{l}p \text { value (within } \\
\text { hospital) }\end{array}$} & \multirow{2}{*}{$\begin{array}{l}p \text { value } \\
\text { (between } \\
\text { hospitals) }\end{array}$} \\
\hline & & & London & Padua & \\
\hline Age, median (P25-P75) (year) & $39(33-48)$ & $36(27.5-44.5)$ & - & - & 0.16 \\
\hline \multicolumn{6}{|l|}{ Sex, no $(\%)$} \\
\hline Female & $17(73.9 \%)$ & $19(79.2 \%)$ & - & - & 0.74 \\
\hline Male & $6(26.1 \%)$ & $5(20.8 \%)$ & & & \\
\hline \multicolumn{6}{|l|}{ Ethnicity, no $(\%)^{\mathrm{a}}$} \\
\hline White & $12(57.1 \%)$ & $24(100 \%)$ & $0.02 *$ & - & $0.002 *$ \\
\hline Asian & $7(33.3 \%)$ & $0(0.0 \%)$ & & & \\
\hline Black/African/Caribbean & $2(9.6 \%)$ & $0(0.0 \%)$ & & & \\
\hline Mixed/multiple ethnic groups & $0(0.0 \%)$ & $0(0.0 \%)$ & & & \\
\hline Missing & 2 & 0 & & & \\
\hline \multicolumn{6}{|l|}{ Smell dysfunction, no (\%) } \\
\hline Yes & $22(95.7 \%)$ & $24(100 \%)$ & - & - & 0.45 \\
\hline No & $1(4.3 \%)$ & $0(0.0 \%)$ & & & \\
\hline \multicolumn{6}{|l|}{ Type of flavour affected, no (\%) } \\
\hline Sweet & $12(52.2 \%)$ & $7(29.2 \%)$ & $1^{\mathrm{b}}$ & $1^{\mathrm{b}}$ & 0.23 \\
\hline Sour & $14(60.9 \%)$ & $5(20.8 \%)$ & & & $0.016^{*}$ \\
\hline Bitter & $15(65.2 \%)$ & $3(12.5 \%)$ & & & $0.001 *$ \\
\hline Salty & $11(47.8 \%)$ & $4(16.7 \%)$ & & & 0.06 \\
\hline Water & $8(34.8 \%)$ & $7(29.2 \%)$ & & & 1 \\
\hline \multicolumn{6}{|c|}{ Numbers of flavours affected, no $(\%)^{\mathrm{a}}$} \\
\hline None (only dysgeusia) & $4(17.4 \%)$ & $14(60.8 \%)$ & 0.88 & $0.001 *$ & 0.065 \\
\hline One & $2(8.7 \%)$ & $2(8.7 \%)$ & & & \\
\hline Two & $4(17.4 \%)$ & $2(8.7 \%)$ & & & \\
\hline Three & $5(21.7 \%)$ & $1(4.4 \%)$ & & & \\
\hline Four & $5(21.7 \%)$ & $3(13.0 \%)$ & & & \\
\hline All of them & $3(13.1 \%)$ & $1(4.4 \%)$ & & & \\
\hline Missing & 0 & 1 & & & \\
\hline \multicolumn{6}{|l|}{ Dysgeusia, no (\%) } \\
\hline Yes & $9(39.1 \%)$ & $21(91.3 \%)$ & - & - & $0.001 *$ \\
\hline No & $14(60.9 \%)$ & $2(8.7 \%)$ & & & \\
\hline Missing & 0 & 1 & & & \\
\hline
\end{tabular}

* Significant $p$ values marked in italics. Level of significance $p<0.05$

${ }^{a}$ Valid percent, not including missing values

${ }^{\text {b}}$ The same $p$ value $(p=1)$ was obtained when comparing each couple of affected flavours, apart from the comparison between bitter and water $(p=0.77)$ in the London group
Acknowledgements We thank Graeme Muir for his assistance with the set-up of the questionnaire.

\section{Compliance with ethical standards}

Conflict of interest The authors declare that they have no conflict of interest.

Open Access This article is licensed under a Creative Commons Attribution 4.0 International License, which permits use, sharing, adaptation, distribution and reproduction in any medium or format, as long as you give appropriate credit to the original author(s) and the source, provide a link to the Creative Commons licence, and indicate if changes were made. The images or other third party material in this article are included in the article's Creative Commons licence, unless indicated otherwise in a credit line to the material. If material is not included in the article's Creative Commons licence and your intended use is not permitted by statutory regulation or exceeds the permitted use, you will need to obtain permission directly from the copyright holder. To view a copy of this licence, visit http://creativecommons.org/licenses/by/4.0/.

\section{References}

Andrews PJ, Pendolino AL, Ottaviano G, Scarpa B et al (2020) Olfactory and taste dysfunction among mild-to-moderate symptomatic COVID-19 positive health care workers: An international survey. Laryngoscope Investig Otolaryngol 5(6):1019-1028. 
Doty RL (2019) Epidemiology of smell and taste dysfunction. Handb Clin Neurol 164:3-13

Rimmer J, Hellings P, Lund VJ, Alobid I, Beale T, Dassi C et al (2019) European position paper on diagnostic tools in rhinology. Rhinol 57(Suppl S28):1-41

Sjöstrand AE, Sjödin P, Hegay T, Nikolaeva A, Shayimkulov F, Blum MGB, Heyer E, Jakobsson M et al (2020) Taste perception and lifestyle: insights from phenotype and genome data among Africans and Asians. Eur J Hum Genet. https://doi.org/ 10.1038/s41431-020-00736-2

von Bartheld CS, Hagen MM, Butowt R (2020) Prevalence of chemosensory dysfunction in COVID-19 patients: a systematic review and meta-analysis reveals significant ethnic differences. ACS Chem Neurosci 11(19):2944-2961
Whitcroft KL, Hummel T (2020) Olfactory dysfunction in COVID-19: diagnosis and management. JAMA 323(24):2512-2514

Xu H, Zhong L, Deng J, Peng J, Dan H, Zeng X, Li T, Chen Q (2020) High expression of ACE2 receptor of 2019-nCoV on the epithelial cells of oral mucosa. Int J Oral Sci 12(1):8

Publisher's Note Springer Nature remains neutral with regard to jurisdictional claims in published maps and institutional affiliations. 